\title{
STRIDER (Sildenafil TheRapy in dismal prognosis early onset fetal growth restriction): an international consortium of randomised placebo-controlled trials
}

\author{
A. Pels ${ }^{1 *}$, L. C. Kenny ${ }^{2}$, Z. Alfirevic ${ }^{3}$, P. N. Baker ${ }^{4}$, Peter von Dadelszen ${ }^{5}$, C. Gluud ${ }^{6}$, C. T. Kariya ${ }^{5}$, B. W. Mol ${ }^{7}$, \\ A. T. Papageorghiou ${ }^{8}$, A. G. van Wassenaer-Leemhuis ${ }^{1}$, W. Ganzevoort ${ }^{1}$, K. M. Groom ${ }^{9}$ and the international \\ STRIDER Consortium
}

\begin{abstract}
Background: Severe, early-onset fetal growth restriction due to placental insufficiency is associated with a high risk of perinatal mortality and morbidity with long-lasting sequelae. Placental insufficiency is the result of abnormal formation and function of the placenta with inadequate remodelling of the maternal spiral arteries. There is currently no effective therapy available. Some evidence suggests sildenafil citrate may improve uteroplacental blood flow, fetal growth, and meaningful infant outcomes. The objective of the Sildenafil TheRapy In Dismal prognosis Early onset fetal growth Restriction (STRIDER) collaboration is to evaluate the effectiveness of sildenafil versus placebo in achieving healthy perinatal survival through the conduct of randomised clinical trials and systematic review including individual patient data meta-analysis.

Methods: Five national/bi-national multicentre randomised placebo-controlled trials have been launched. Women with a singleton pregnancy between 18 and 30 weeks with severe fetal growth restriction of likely placental origin, and where the likelihood of perinatal death/severe morbidity is estimated to be significant are included. Participants will receive either sildenafil $25 \mathrm{mg}$ or matching placebo tablets orally three times daily from recruitment to 32 weeks gestation.

Discussion: The STRIDER trials were conceived and designed through international collaboration. Although the individual trials have different primary outcomes for reasons of sample size and feasibility, all trials will collect a standard set of outcomes including survival without severe neonatal morbidity at time of hospital discharge. This is a summary of all the STRIDER trial protocols and provides an example of a prospectively planned international clinical research collaboration. All five individual trials will contribute to a pre-planned systematic review of the topic including individual patient data meta-analysis.
\end{abstract}

Trial registrations: New Zealand and Australia: ACTRN12612000584831. Registered 30/05/2012.

Canada: NCT02442492. Registered 05/05/2015.

Ireland: CT 900/572/1. Registered 15/07/2015.

The Netherlands: NCT02277132. Registered 29/09/2014.

United Kingdom: ISRCTN39133303. Registered 31/07/2014.

Keywords: Fetal growth restriction, Placental insufficiency, Sildenafil, Randomised placebo controlled trial, Neonatal mortality, Neonatal morbidity

\footnotetext{
* Correspondence: a.pels@amc.uva.nl

${ }^{1}$ Academisch Medisch Centrum, Meibergdreef 9, 1105, AZ, Amsterdam, The

Netherlands

Full list of author information is available at the end of the article
} 


\section{Background}

An estimated $0.4 \%$ of pregnancies worldwide are complicated by severe early-onset ( $<28$ weeks gestation) fetal growth restriction (FGR) caused by placental insufficiency. This patient group utilises disproportionate amounts of obstetric care and has a high likelihood of premature birth, both for fetal and for secondary maternal indications such as the development of the maternal syndrome of pre-eclampsia. As these growth-restricted infants are usually born very preterm, they carry additional significant risks of major and minor neonatal morbidity, and long-term health sequelae if they survive. These risks are not only related to gestational age at birth, but also to the degree of FGR. Survival proportions for severely growth-restricted fetuses very remote from term ( $<28$ weeks' gestation) vary between 7 and $33 \%[1-3]$ and less than one third of these fetuses will survive their neonatal intensive care unit (NICU) stay without significant neurodevelopmental sequelae [4].

The diagnosis of early onset FGR is often missed but even when diagnosed based on growth parameters below the normal range $(<10$ th, $<5$ th, or $<3$ rd centile) with or without evidence of abnormal fetal and maternal Doppler waveforms there are currently no specific evidence-based therapies available. Non-specific interventions may include lifestyle modifications such as reducing or stopping work, stopping aerobic exercise, rest at home, and hospital admission for rest and surveillance. These interventions are used in the belief that rest will reduce the steal from the utero-placental circulation to the glutei and quadriceps muscles but are not based on any good quality evidence. In the absence of proven therapeutic interventions, standard clinical management consists of counselling, intensive monitoring, and timely delivery once a fetus has reached a viable gestation and size but often results in extreme preterm birth.

Doppler waveform analysis of pregnancies complicated by severe FGR suggests compromised utero-placental circulation and placental hypo-perfusion $[5,6]$. Sildenafil, a phosphodiesterase inhibitor, potentiates the action of nitric oxide thus causing vasodilatation [7]. It is therefore possible that sildenafil may affect uteroplacental circulation and perfusion resulting in improved gaseous and nutrient exchange and improved fetal growth and well-being. Animal and preclinical studies support this concept [8-13].

Although the number of women using sildenafil in pregnancy is low, it is increasingly used in pregnancy for maternal cardiac indications with no reports of adverse maternal or fetal effects [14-21]. In a small randomised clinical trial in women with early onset pre-eclampsia, sildenafil use had no demonstrable effect on prolongation of pregnancy, but provided further reassurance on drug safety profile in pregnancy [16]. Sildenafil has been used in a small cohort of women in the setting of early onset FGR. In an observational study by STRIDER collaborators in Vancouver, Canada, there was a tendency towards more live-born children with survival intact to primary discharge for women treated with sildenafil when compared to women with pregnancies at similar risk but not receiving sildenafil [17]. From the limited observations to date there are no concerns of adverse maternal, fetal, neonatal, or infant effects associated with sildenafil use in pregnancy [14-21].

On the basis of this preliminary research, some centres have already adopted treatment with sildenafil $[18,19]$. However, there is no clear evidence of true health benefits and, more significantly, potential harm has not yet been excluded. Use of sildenafil for other indications in clinical trials and in post-market reporting has highlighted adverse drug reactions including headache, flushing, nasal congestion, and impaired vision and, rare, serious consequences such as myocardial infarction, arrhythmias, and stroke [7]. More specific to pregnancy and FGR, sildenafil's vasodilatory properties may cause a transient decrease in blood pressure with potential to adversely affect the most at risk fetuses (those with absent or reversed end diastolic flow on Doppler waveform analysis), via a reduction in critical uteroplacental flow or by a direct effect on fetal vasculature. Prolonging pregnancy in FGR has the potential to shift the survival curve but will not necessarily have the same positive impact on short term outcomes and long term well-being. Well-designed, appropriately powered randomised placebo-controlled trials are required before implementation into clinical practice should be considered.

The overarching hypothesis of this collaboration of clinical trials is that sildenafil citrate compared with placebo will improve fetal growth and wellbeing, allowing prolongation of pregnancy leading to a decrease in the rate of fetal and neonatal mortality and severe morbidity.

\section{Methods/design}

Design of the trials

Randomised placebo-controlled trials in New Zealand/ Australia, Canada, Ireland, the Netherlands, and the United Kingdom including participants during 2014 to 2020. Trials are independently funded and executed and will be independently reported but all will contribute to a prospectively planned systematic review including individual patient data (IPD) meta-analysis [22]. Each trial is prospectively registered New Zealand and Australia: ACTRN12612000584831, Canada: NCT02442492, Ireland: CT 900/572/1, the Netherlands: NCT02277132 and the United Kingdom: ISRCTN39133303. Study protocols can be freely accessed URL [23-27]. 


\section{Setting}

Clinical trials are taking place in tertiary care centres in New Zealand/Australia, Canada, Ireland, the Netherlands, and the United Kingdom. A single trial management service hosted at the University of British Columbia, Canada, is being used by each trial and provides a randomisation service and electronic data collection system. IPD meta-analysis and systematic review will be performed by a trial and systematic review service unit in Denmark, The Copenhagen Trial Unit.

\section{Participants}

Pregnant women referred to tertiary care referral centres for evaluation and management of severe early-onset FGR at gestational ages $<30$ weeks.

\section{Inclusion and exclusion criteria}

Individual trial inclusion and exclusion criteria are shown in Table 1. The differing inclusion criteria between individual trials allow for variations in feasibility, local standards, and investigator choice.

\section{Ethics and informed consent}

All trials have obtained appropriate local ethics approvals. All participating women are provided with written and verbal information regarding the trial they are going to enter and provide signed informed consent in advance of participation. Any protocol modifications once the trials are underway will be reviewed by the local Ethics Committee. Appropriate clinical trial insurance is in place for participants of each trial in the event that any participants experiences harm as a consequence of participation in these trials.

\section{Randomisation}

$R$ programming statistical software was used for generating the allocation lists. The $\mathrm{R}$ package blockrand function was modified to allow for varying numbers of strata. For each trial an allocation list was generated for each level of stratification variable. Each allocation list had a length of sample size $+20 \%$. Block sizes used are specific to each individual trial.

\section{Experimental and control interventions}

Participants will receive oral sildenafil $25 \mathrm{mg}$ or matching placebo tablets (table 1 ) three times daily from randomisation until delivery, fetal demise, or 32 weeks gestation (whichever occurs first). Participants, researchers, dispensing pharmacists, clinicians and outcome assessors will remain unaware of treatment allocation for duration of trial. All other interventions will be provided according to local practice. Treatment code may be revealed in event of a serious adverse event where the responsible clinician deems this information to be crucial to provide on-going safe clinical care.

\section{Sample size estimation}

Assumptions for sample size estimations were made on the basis of clinical relevance, local audit, and a pilot cohort [17]. Investigators for each individual trial made their own estimations, based on the choice of primary outcome and the following variables:

The New Zealand/Australian STRIDER trial has a primary outcome of fetal growth velocity determined by abdominal circumference (AC) growth velocity. Using data from the pilot cohort [17] to estimate a difference of $50 \%$ in placebo-treated versus $80 \%$ in sildenafiltreated of pregnancies with an increased postrandomisation AC growth velocity, 58 women will be randomised per group, (two-sided $\alpha$ of 0.05 and $90 \%$ power to detect this difference). Allowing for a 5\% dropout rate, the total sample size will be 122 women.

Three of the STRIDER trials have a primary outcome relating to the interval between randomisation and birth. In the UK STRIDER and Irish STRIDER trials, 1 week (7 day) difference in mean randomisation and birth interval is considered to be clinically important. Internal audits of early-onset FGR cohorts revealed an average diagnosis-delivery interval of 20 days with standard deviation of 11 days. In order to confirm or refute that sildenafil can prolong pregnancy by 1 week compared with placebo, 52 women will be randomised per group in each trial (two-sided $\alpha$ of 0.05 and $90 \%$ power to detect this difference). Allowing for a 5\% drop-out rate, the total sample size will be 112 women in each trial. Based on local pilot cohort experience, the Canadian STRIDER trial assumes a 16-day difference in mean gestational age at delivery, 189 days (placebo-treated) and 205 days (sildenafil-treated) [17]. 41 women will be randomised per group (two-sided $\alpha$ of 0.05 and $80 \%$ power to detect this difference). Allowing for a $10 \%$ drop-out rate, the total sample size will be 90 women.

The Dutch STRIDER trial has a primary outcome of intact infant survival until hospital discharge. Assuming a 29\% (placebo-treated) and 44\% (sildenafil-treated) proportion of intact infant survival until hospital discharge, 161 women will be randomised per group (two-sided $\alpha$ of 0.05 and $80 \%$ power to detect this difference). Allowing for a $10 \%$ drop-out rate, the total sample size will be 354 women.

\section{Outcomes}

Primary outcomes of individual trials are summarised in Table 1. Individual trials have different primary outcomes but all trials collect a standard set of outcomes and apply the same definition for each outcome to ensure compatibility for future analysis. 
Table 1 Trial characteristics of each STRIDER trial

\begin{tabular}{|c|c|c|c|c|c|}
\hline & $\begin{array}{l}\text { Australia/ } \\
\text { New Zealand }\end{array}$ & Canada & Ireland & The Netherlands & United Kingdom \\
\hline $\begin{array}{l}\text { Number of } \\
\text { participants }\end{array}$ & 122 & 90 & 112 & 354 & 112 \\
\hline $\begin{array}{l}\text { Number of } \\
\text { recruiting sites }\end{array}$ & 12 & 10 & 6 & 10 & 18 \\
\hline GA (weeks) & $22^{+0}-29^{+6}$ & $18^{+0}-27^{+6}$ & $22^{+0}-29^{+6}$ & $20^{+0}-29^{+6}$ & $22^{+0}-29^{+6}$ \\
\hline $\begin{array}{l}\text { Inclusion } \\
\text { criteria }\end{array}$ & $\begin{array}{l}\text { - Singleton pregnancy } \\
\text { - Expectant } \\
\text { management } \\
\cdot 22^{+0}-27^{+6} \text { weeks: } \\
\text { AC } \leq 3 \mathrm{rd} \% \text { ile } \\
\cdot 28^{+0}-29^{+6} \text { weeks: } \\
\text { EFW }<700 \mathrm{~g} \text {. }\end{array}$ & $\begin{array}{l}\text { - Singleton pregnancy } \\
\text { - Expectant management } \\
\text { - AC <10th \%ile AND/OR } \\
\text { - Reduced fetal growth } \\
\text { (AC interval < } 50 \% \text { of } \\
\text { expected) with either } \\
\text { prior severe early onset } \\
\text { FGR with adverse } \\
\text { perinatal outcome OR } \\
\text { abnormal uterine artery } \\
\text { waveform in index } \\
\text { pregnancy; OR EFW } \\
<700 \mathrm{~g} \text { ) } \\
\text { - Serum PIGF levels } \\
<5 \text { th \%tile for GA }\end{array}$ & $\begin{array}{l}\text { - Singleton pregnancy } \\
\text { - Expectant } \\
\text { management } \\
\text { - EFW OR AC }<10 \text { th centile } \\
\text { - absent or reversed EDF } \\
\text { in umbilical artery }\end{array}$ & $\begin{array}{l}\text { - Singleton pregnancy } \\
\text { - Expectant management } \\
\text { - } 20^{+0}-27^{+6} \mathrm{wk} \text { : AC <3rd \%ile } \\
\text { OR EFW <5th \%ile } \\
\text { - } 28^{+0}-29^{+6} \mathrm{wk} \text { : EFW <700 g } \\
\text { - Likely placental origin } \\
\text { defined by } \\
\text { a. uterine artery notching OR } \\
\text { b. abnormal flow of umbilical } \\
\text { artery or middle cerebral } \\
\text { artery OR } \\
\text { c. maternal hypertensive } \\
\text { disorder OR } \\
\text { d. low PIGF in point-of-care } \\
\text { assessment }\end{array}$ & $\begin{array}{l}\text { - Singleton pregnancy } \\
\text { - Expectant } \\
\text { management } \\
\text { - EFW OR AC <10th } \\
\text { centile } \\
\text { - absent or reversed } \\
\text { EDF in umbilical } \\
\text { artery }\end{array}$ \\
\hline $\begin{array}{l}\text { Exclusion } \\
\text { criteria }\end{array}$ & $\begin{array}{l}\text { - Known major fetal } \\
\text { anomaly/syndrome/ } \\
\text { congenital infection } \\
\text { deemed as likely } \\
\text { cause for FGR } \\
\text { - Known fetal aneuploidy } \\
\text { - Any contra-indication } \\
\text { to sildenafil use }\end{array}$ & $\begin{array}{l}\text { - Maternal age } \leq 18 \text { years } \\
\text { - Known fetal aneuploidy, } \\
\text { fetal anomaly/syndrome/ } \\
\text { congenital infection } \\
\text { - Any contra-indication to } \\
\text { sildenafil use } \\
\text { - Cocaine/ crystal meth use } \\
\text { - Pre-eclampsia or } \\
\text { gestational hypertension } \\
\text { - HIV positive/ maternal } \\
\text { heart disease } \\
\text { - Receiving Prazosin, } \\
\text { peripheral alpha-blockers, } \\
\text { nitrates, vasoconstrictors }\end{array}$ & $\begin{array}{l}\text { - Maternal age } \leq 18 \text { years } \\
\text { - Known or suspected } \\
\text { structural or chromosomal } \\
\text { fetal abnormality } \\
\text { - Any contra-indication } \\
\text { to sildenafil use } \\
\text { - Cocaine use }\end{array}$ & $\begin{array}{l}\text { - Maternal age } \leq 18 \text { years } \\
\text { - Known congenital } \\
\text { malformation or infection } \\
\text { - Any contra-indication to } \\
\text { sildenafil use } \\
\text { - Cocaine use } \\
\text { - Use of cyp3A5 inhibitor }\end{array}$ & $\begin{array}{l}\text { - Maternal age } \\
\leq 16 \text { years } \\
\text { - Known or suspected } \\
\text { structural or } \\
\text { chromosomal fetal } \\
\text { abnormality } \\
\text { - Any contra-indication } \\
\text { to sildenafil use } \\
\text { - Cocaine use }\end{array}$ \\
\hline $\begin{array}{l}\text { Treatment } \\
\text { period }\end{array}$ & $\begin{array}{l}\text { Until delivery, demise } \\
\text { or } 31^{+6} \text { weeks of } \\
\text { gestation, whichever } \\
\text { comes first }\end{array}$ & $\begin{array}{l}\text { Until delivery, or } 31^{+6} \text { weeks } \\
\text { of gestation, whichever } \\
\text { comes first }\end{array}$ & $\begin{array}{l}\text { Until delivery, or } 31^{+6} \\
\text { weeks of gestation, } \\
\text { whichever comes first }\end{array}$ & $\begin{array}{l}\text { Until delivery, or } 31^{+6} \\
\text { weeks of gestation, } \\
\text { whichever comes first }\end{array}$ & $\begin{array}{l}\text { Until delivery, or } \\
31^{+6} \text { weeks of } \\
\text { gestation, whichever } \\
\text { comes first }\end{array}$ \\
\hline $\begin{array}{l}\text { Stratification } \\
\text { criteria }\end{array}$ & $\begin{array}{l}\text { i. Umbilical artery EDF } \\
\text { ii. GA range } \\
<24 \text { weeks vs } \\
\geq 24 \text { weeks }\end{array}$ & i. Centre & $\begin{array}{l}\text { i. Centre } \\
\text { ii. GA range } \\
\left(22^{+0}-25^{+6}\right) \text { vs }\left(26^{+0}-29^{+6}\right)\end{array}$ & i. Centre & $\begin{array}{l}\text { i. Centre } \\
\text { ii. GA range }\left(22^{+0}-25^{+6}\right) \\
\text { vs }\left(26^{+0}-29^{+6}\right)\end{array}$ \\
\hline $\begin{array}{l}\text { Primary } \\
\text { outcome }\end{array}$ & $\begin{array}{l}\text { Fetal growth velocity } \\
\text { determined by AC } \\
\text { growth velocity }\end{array}$ & ${ }^{\mathrm{a}} \mathrm{GA}$ at delivery & $\begin{array}{l}\text { Prolongation of pregnancy } \\
\text { for } 1 \text { week as a surrogate } \\
\text { for long term morbidity }\end{array}$ & $\begin{array}{l}\text { Intact perinatal survival } \\
\text { to term age without } \\
\text { evidence of either severe } \\
\text { CNS injury or non-CNS } \\
\text { severe morbidity }\end{array}$ & $\begin{array}{l}\text { Prolongation of } \\
\text { pregnancy for } 1 \text { week } \\
\text { as a surrogate for } \\
\text { long term morbidity }\end{array}$ \\
\hline Randomisation & $\begin{array}{l}{ }^{\mathrm{b}} \text { Centralised, } \\
\text { computer based }\end{array}$ & & & & \\
\hline Blinding & $\begin{array}{l}\text { Specifically manufactured } \\
\text { visually matching active } \\
\text { drug and placebo }\end{array}$ & $\begin{array}{l}\text { Visually matching active } \\
\text { drug and placebo by } \\
\text { over encapsulation }\end{array}$ & $\begin{array}{l}\text { Visually matching active } \\
\text { drug and placebo by } \\
\text { over encapsulation }\end{array}$ & $\begin{array}{l}\text { Specifically manufactured } \\
\text { visually matching active } \\
\text { drug and placebo }\end{array}$ & $\begin{array}{l}\text { Visually matching } \\
\text { active drug and } \\
\text { placebo by over } \\
\text { encapsulation }\end{array}$ \\
\hline $\begin{array}{l}\text { Data } \\
\text { mangement }\end{array}$ & $\begin{array}{l}{ }^{\mathrm{b}} \text { Centralised, } \\
\text { computer based }\end{array}$ & & & & \\
\hline
\end{tabular}

GA Gestational age, EFW Estimated Fetal Weight, AC Abdominal Circumference, PIGF Placental Growth Factor, EDF End Diastolic Flow, HIV Human Immunodeficiency Virus, CNS Central Nervous System

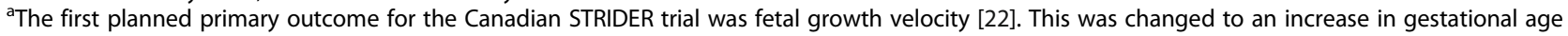
at delivery following a funding review and assessment of feasibility

${ }^{\mathrm{b}}$ Randomisation services and electronic data collection and management service (RedCap) provided to each individual trial by single co-ordinating centre at University of British Columbia, Canada 


\section{Independent data monitoring and safety committees}

All individual trials have their independent data safety monitoring committees and interim analyses of trial data are planned in some individual trial protocols. Individual trial data monitoring and safety committee charters can be freely accessed [28-32]. An umbrella international data safety monitoring board has been established to provide oversight for all STRIDER trials and will review trial sequential data analysis after the completion of each trial once two trials have been completed.

\section{Type of analyses}

Independent blinded data analysis at the completion of each individual trial will occur on an intention-to-treat basis: that is, for the purpose of analysis, all women will be included in the group to which they have been randomised. Pre-planned subgroup analysis will occur within some individual trials including; assessment of the effect of low placental growth factor (PIGF) at inclusion, umbilical artery Doppler waveform analyses at inclusion (presence or absence of forward flow), and for the effect of other baseline parameters such as gestational age, estimated fetal weight, and participating centre.

\section{Ancillary and follow-up studies}

Each individual trial has ancillary studies underway. These include the effect of sildenafil on: maternal peripheral blood angiogenic factors, myometrial and placental vasculature, maternal haemodynamics, and neonatal cardiac function. Local bio-banking of placental tissue and/or umbilical cord blood is also planned in some trials.

Childhood outcome studies are proposed to assess the important longer-term outcomes of infants born to mothers participating in the STRIDER trials. This will include assessment of neurodevelopmental, cardiovascular, and metabolic outcomes. Assessment at 2-3 years of age is already funded or partially funded in the Netherlands and Ireland. Further funding applications are pending.

\section{Recruitment status}

New Zealand and Australia: Recruitment completed data analysis in progress.

Canada: Recruiting.

Ireland: Not yet recruiting.

The Netherlands: Recruiting.

United Kingdom: Recruitment completed -primary outcome data submitted for publication.

\section{Discussion}

The STRIDER trials were conceived and designed through international collaboration. The trials are competitively funded at a national level by government funded research agencies within each country. Each individual trial protocol was developed independently by local groups of investigators but all trial designs are similar and all outcomes will be collected in all trials. Each trial will be conducted autonomously, but in close co-operation across the six countries involved. There is a central trial management service hosted at the University of British Columbia, Canada, providing a central randomisation service as well as a central electronic data collection system for each trial. The randomisation service and data collection systems have been designed collaboratively and, although each trial will use its own independent randomisation service and data collection systems these shared resources have reduced overall trial costs and will ensure data compatibility for future analysis in the prospectively planned IPD meta-analyses.

The research teams for all STRIDER trials have regular communication via e-mail, teleconferencing, face-to-face meetings, and a newsletter. Collaboration between the groups is strong with all teams committed to securing funding for long-term infant and childhood outcome studies. These data will contribute to further the systematic review and IPD meta-analysis.

The STRIDER trials are all conducted in order to reduce bias by employing central, stratified randomisation; blinding of all parties through use of matching placebos; central data management focusing on few missing data and dropouts; blinded drawing of conclusions; transparent uploading of IPD data after the trials have been published; no involvement of the pharmaceutical industries selling the product; as well as planning for systematic review of all trials including meta-analyses of individual patient data. These bias eliminating or reducing actions have all been conducted to minimize any risks of systematic errors, that is overestimation of benefits and underestimation of harms [33-40].

The STRIDER trials have all calculated their sample sizes taking into consideration a projected drop-out rate. This gives sample sizes that are inflated according to the assumed risks. We acknowledge this methodology should no longer be undertaken as there is now international consensus to analyse data with multiple imputation [41, 42]. Such analyses will be used for the individual trials, however, we have not amended the sample size calculations as the projected drop-out is small in all trials.

In medicine, a single randomised clinical trial is unlikely to be able to change clinical practice [38] Therefore, the STRIDER trials have from inception been planned to be systematically reviewed together with any other randomised trials addressing the same topic [22]. Furthermore, in order to better evaluate benefits and harms, the STRIDER trials are planned to be included alone or together with any other trial providing data into 
individual patient data meta-analyses [22]. The STRIDER Consortium is presently writing up a detailed statistical analysis plan for the systematic review and individual patient data meta-analyses.

The STRIDER Collaboration will ensure the assessment of sildenafil use for the treatment of early onset FGR occurs in a safe and timely manner and should ensure sildenafil is only introduced into clinical practice if reliable data on safety and efficacy supports its use. The extensive IPD data will also provide opportunities to broaden our knowledge of severe early onset FGR, and to explore other applications for sildenafil use if safety and efficacy are established.

\section{Abbreviations}

AC: Abdominal Circumference; CNS: Central Nervous System; EDF: End Diastolic Flow; EFW: Estimate of Fetal Weight; FGR: Fetal Growth Restriction; NICU: Neonatal Intensive Care Unit; PIGF: Placental Growth Factor

\section{Acknowledgements}

We acknowledge and thank the STRIDER trials participants and their families and all funding agencies.

\section{Funding}

New Zealand/Australia: Health Research Council New Zealand Project Grant 13/ 242, Cure Kids Grant 3565, Nurture Foundation Grant (Neonatal Sub-study).

Canada: Canadian Institutes of Health Research (ClHR).

Ireland: Health Research Board HRA-2014-DI-620.

The Netherlands: ZonMW 80-83,600-98-20,081.

United Kingdom: EME MRC NIHR 12-62-109.

Denmark: Copenhagen Trial Unit, Centre for Clinical Intervention Research, Copenhagen, Denmark.

Funders do not have any influence on study design; collection,

management, analysis, and interpretation of data; writing of the report; and the decision to submit the report for publication.

\section{Availability of data and materials}

The datasets that will be generated and/or analysed from these studies will be publicly available once all trials are complete, individual completed trial datasets will be available from the chief investigator of each trial upon reasonable request.

\section{Authors' contributions}

ZA, ATP, PB: STRIDER UK. WG, AP, AW: STRIDER Netherlands. KG, PB: STRIDER New Zealand/Australian. PD, CK: STRIDER Canada. LK: STRIDER Ireland. BM, CG: Methodologist. The International Strider Consortium. All authors contributed to the manuscript. All named authors reviewed and approved the manuscript.

The international STRIDER Consortium consists of the following STRIDER groups:

\section{New Zealand/Australia}

Chief Investigator: Dr. K.M. Groom, University of Auckland and National Women's Health, Auckland City Hospital, New Zealand.

Steering Committee: Dr. K.M. Groom, Prof P.N. Baker, Prof L.M. McCowan, Prof P.R. Stone, Dr. A. Lee (statistician), Ms. L. Mackay (trial manager), University of Auckland, New Zealand.

Site Investigators: Dr. K.M. Groom, National Women's Health, Auckland City Hospital, New Zealand; Dr. G. Gardener, Mater Mother's Hospital, Brisbane, Australia; Prof J. Dickinson, King Edward Memorial Hospital, Perth, Australia; Dr. P. Muller, Women's and Children's Hospital, Adelaide, Australia; Dr. R. Sekar, Royal Brisbane Women's Hospital, Brisbane, Australia; Dr. R.A. Reid, Christchurch Women's Hospital, Christchurch, New Zealand; Dr. J. Unterschneider, Royal Women's Hospital, Melbourne, Australia; Prof A. Welsh, Royal Hospital for Women, Sydney, Australia; Dr. J. Marlow, Wellington Hospital, Wellington, New Zealand; Prof Jon Hyett, Royal Prince Alfred Hospital, Sydney, Australia; Prof S. Walker, Mercy Hospital for Women,
Melbourne, Australia; Prof. J. Morris, Royal North Shore Hospital, Sydney; Dr. D. Watson, Townsville Hospital, Townsville, Australia.

Other investigators: Dr. C. Oyston, University of Auckland, New Zealand; Dr. C. McKinlay University of Auckland and National Women's Health, Auckland City Hospital, New Zealand; Dr. S. Harris, University of Otago and Christchurch Women's Hospital, Christchurch, New Zealand, Dr. A. Gill, King Edward Memorial Hospital, Perth, Australia.

\section{Canada}

Chief Investigators: Prof P. von Dadelszen, BC Children's Hospital Research Institute (BCCHR), University of British Columbia and St George's, University of London, London; Prof K.I. Lim, BC Women's Hospital, Vancouver; Prof L.A. Magee, CFRI, University of British Columbia and St George's, University of London, London; S. Lalji, BC Women's Hospital, Vancouver.

Steering Committee: Prof P. von Dadelszen; Prof K.I. Lim; Prof. L.A. Magee;

S. Lalji; C. T. Kariya, University of British Columbia, Vancouver; T. Lee, University of British Columbia, Vancouver; J. Li, University of British Columbia, Vancouver; A. Hutfield, University of British Columbia, Vancouver; Prof. M. Ansermino, University of British Columbia, Vancouver; F. Audibert, University of Montreal, Montreal; Prof E. Bujold, University Laval, Quebec; Prof S.T. Davidge, University of Alberta, Edmonton; B. Piedboeuf, University Laval, Québec; W. Robinson, University of British Columbia, Vancouver; G.R. Seaward, University of Toronto, Toronto; Prof J. Singer, University of British Columbia, Vancouver; Prof A.R. Synnes, University of British Columbia, Vancouver; Site Investigators: Prof K.I. Lim, BC Women's Hospital, Vancouver; S. Lalji, BC Women's Hospital, Vancouver; Dr. J. Burrows, University of British Columbia, Vancouver; S. Dwinnell, Foothills Hospital, Calgary; Prof R. Gagnon, McGill University, Montréal.

L. Gaudet, University of Ottawa, Ottawa; B. Piedboeuf, University Laval, Québec; C. Young, Royal Alexandra Hospital University of Alberta; G.R. Seaward, University of Toronto, Toronto.

Ireland

Chief Investigator: Prof L. Kenny, the Irish Centre for Fetal and Translational Research (INFANT) University College Cork, Cork.

Steering Committee: Prof L. Kenny, INFANT, University College Cork, Cork; Prof D. Murphy, Trinity College, Dublin; Prof F. McAuliffe, University College Dublin, Dublin; Prof F. Malone, the Rotunda Hospital, Dublin; Dr. A. Khashan, University College Cork, Cork; Prof J. Eustace, University College Cork, Cork; Prof E. Dempsey, INFANT, University College Cork, Cork; Dr. K O’Donoghue, Cork University Maternity Hospital, Cork.

Site Investigators: Dr. K. O'Donoghue, Cork University Maternity Hospital, Cork; Prof D. Murphy, the Coombe Maternity Hospital, Dublin; Prof. F. McAuliffe, the National Maternity Hospital, Dublin; Prof F. Malone, the Rotunda Hospital, Dublin. Other Investigators: Dr. F. Breathnach, the Rotunda Hospital, Dublin; Prof S. Daly, Trinity College Dublin.

The Netherlands

Chief investigator: Dr. J.W. Ganzevoort, Academisch Medisch Centrum. Steering committee: Dr. J.W. Ganzevoort, Academisch Medisch Centrum; A. Pels, Academisch Medisch Centrum, Amsterdam.

Site investigators: Dr. S. Al-Nasiry Maastricht Universitair Medisch Centrum, Maastricht; Dr. M.A. de Boer, VU Medisch Centrum, Amsterdam; Dr. M. Sueters, Leids Universitair Medisch Centrum, Leiden; Dr. J.B. Derks, Universitair Medisch Centrum Utrecht, Utrecht; Dr. J. van Drongelen, Radboud Universitair MC, Nijmegen; Dr. H.J. Duvekot, Erasmus Medisch Centrum, Rotterdam; Dr. A. Elvan-Taspinar, Universitair Medisch Centrum Groningen, Groningen; Dr. J. van Eyck, Isala Klinieken, Zwolle; Prof Dr. C.J.M. de Groot, VU Medisch Centrum, Amsterdam; Dr. J. van Laar, Perinataal Centrum MMC, Veldhoven; Dr. L.P. Morssink, Medisch Centrum Leeuwarden, Leeuwarden. United Kingdom

Chief Investigator: Prof Z. Alfirevic, Liverpool University.

Steering Committee: Prof A. Cameron, University of Glasgow: Prof E. Draper, National Perinatal Epidemiology Unit, University of Leicester; Dr. P. Clarke, Norfolk and Norwich University NHS Trust Hospital, Norwich; Dr. L. Price, A. Astor, Liverpool University; L. Hardman, Liverpool University; Professor Z. Alfirevic, Liverpool University; Dr. A. Sharp, Liverpool University; Dr. R. Jackson, Prof L. Kenny, INFANT, University College Cork, Cork; Dr. A. Papageorghiou, St Georges Hospital, London.

Site Investigators: Prof Z. Alfirevic, Liverpool Women's NHS FT, Liverpool; Dr. G. Masson, University Hospital of North Staffordshire, Stoke-on-Trent; Dr. J. Aquilin, St Bartholomew's and the Royal London Hospital, London; Dr. A. Papageorghiou, St Georges Hospital, London; Dr. E. Johnstone, St Mary's Hospital, Manchester, Mr. G. Bugg, Nottingham University Hospitals 
NHS Trust, Nottingham; Dr. D. Howe, Princess Anne Hospital, Southampton: Dr. S. Patni, Birmingham Heartlands Hospital Birmingham; Mr. H. Mousa, Leicester Royal Infirmary, Leicester; Dr. H. Russell, NHS Fife Victoria Hospital, Fife; T. Hannon, RVI Newcastle-upon-Tyne Hospital NHS FT, Newcastle-uponTyne; Prof M. Kilby, Birmingham Women's NHS Foundation Trust, Birmingham; Dr. A. David, UCL University College, London; Dr. K. Cohen, Leeds General Infirmary, Leeds; Mr. A. Mckelvey, Norfolk and Norwich University NHS Trust Hospital, Norwich; Mr. L. Impey, John Radcliffe Women's Centre, Oxford University Hospital NHS Trust, Oxford; Dr. S. Stock, Queens Medical Research Institute, Edinburgh; Dr. L. Poon, Kings College London, London; Dr. D. Pasupath, St Thomas Hospital, London.

Other investigators: Dr. A.Khalil, St George's Hospital, London; Dr. M.Turner, Liverpool University: Prof P.N. Baker, University of Leicester; Prof L. Kenny, INFANT, University College Cork, Cork.

\section{Ethics approval and consent to participate}

New Zealand/Australia: New Zealand Health and Disability Ethics Committee (CEN/12/06/028/AM05), Royal Brisbane \& Women's Hospital Human Research Ethics Committee (HREC/14/ORBW/178), and King Edward Memorial Hospital Ethics Committee (2014071EW).

Canada: University of British Columbia/Children's and Women's Health Centre of BC Research Ethics Board (H15-00899).

Ireland: provisional approval by Cork University Teaching Hospital Ethics Committee (ECM 5 (9) 02/02/16), full approval will be granted on confirmation of sponsorship (pending).

The Netherlands: MET AMC (NL41894.018.14)

The United Kingdom: 14.NE.0011.

All participating women are provided with written and verbal information regarding the trial they are going to enter and provide signed informed consent in advance of participation. Any protocol modifications once the trials are underway will be reviewed by the local Ethics Committee. Appropriate clinical trial insurance is in place for participants of each trial in the event that any participant experiences harm as a consequence of participation in these trials.

\section{Consent for publication}

Not applicable.

\section{Competing interests}

The authors declare that they have no competing interests.

\section{Publisher's Note}

Springer Nature remains neutral with regard to jurisdictional claims in published maps and institutional affiliations.

\begin{abstract}
Author details
${ }^{1}$ Academisch Medisch Centrum, Meibergdreef 9, 1105, AZ, Amsterdam, The Netherlands. ${ }^{2}$ University College Cork, Cork, Ireland. ${ }^{3}$ University of Liverpool, Liverpool, UK. ${ }^{4}$ College of Life Sciences, University of Leicester, Leicester, UK. ${ }^{5}$ Department of Women's and Children's Health, School of Life Course Sciences, King's College London, London, UK. ${ }^{6}$ Copenhagen Trial Unit, Centre for Clinical Intervention Research, Rigshospitalet, Copenhagen University Hospital, Copenhagen, Denmark. ${ }^{7}$ The Robinson Research Institute, School of Paediatrics and Reproductive Health, University of Adelaide, Adelaide, SA 5000, Australia. ${ }^{8}$ University of Oxford, Oxford, UK. ${ }^{9}$ University of Auckland, Auckland, New Zealand.
\end{abstract}

\section{Received: 6 July 2016 Accepted: 23 November 2017}

Published online: 28 December 2017

\section{References}

1. Lee MJ, Conner EL, Charafeddine L, Woods JR Jr, Del Priore G. A critical birth weight and other determinants of survival for infants with severe intrauterine growth restriction. Ann N Y Acad Sci. 2001;943:326-39.

2. Petersen SG, Wong SF, Urs P, Gray PH, Gardener GJ. Early onset, severe fetal growth restriction with absent or reversed end-diastolic flow velocity waveform in the umbilical artery: perinatal and long-term outcomes. Aust $N$ Z J Obstet Gynaecol. 2009;49(1):45-51. https://doi.org/10.1111/j.1479-828X. 2008.00938.x.
3. Batton DG, DeWitte DB, Espinosa R, Swails TL. The impact of fetal compromise on outcome at the border of viability. Am J Obstet Gynecol. 1998;178(5):909-15. https://doi.org/10.1016/S0002-9378(98)70522-8.

4. Shah PS, et al. Prediction of survival without morbidity for infants born at under 33 weeks gestational age: a user friendly grpahical tool. Arch Dis Child Fetal Neonatal Ed. 2012;97:F110-5. doi:10.1136/archdischil-2011300143

5. Bower S, Kingdom J, Campbell S. Objective and subjective assessment of abnormal uterine artery Doppler flow velocity waveforms. Ultrasound Obstet Gynecol. 1998;12(4):260-4.

6. Moore RJ, Strachan BK, Tyler DJ, Duncan KR, Baker PN, Worthington BS, Johnson IR, Gowland PA. In utero perfusing fraction maps in normal and growth restricted pregnancy measured using IVIM echo-planar MRI. Placenta. 2000;21(7):726-32.

7. Product monograph Viagra. Sildenafil as sildenafil citrate. Pfizer Canada Inc., 2015.

8. Stanley JL, Andersson IJ, Poudel R, Rueda-Clausen CF, Sibley CP, Davidge ST, Baker PN. Sildenafil citrate rescues fetal growth in the catechol-o-methyl transferase knockout mouse model. Hypertension. 2012;59:1021-8.

9. Refuerzo JS, Sokol RJ, Aranda JV, Hallak M, Hotra JW, Kruger M, Sorokin Y. Sildenafil citrate and fetal outcome in pregnant rats. Fetal Diagn Ther. 2006; 21:259-63.

10. Sanchez-Aparicio P, Mota-Rojas D, Nava-Ocampo AA, Trujillo-Ortega ME, Alfaro-Rodriguez A, Arch E, Alonso-Spilsbury M. Effects of sildenafil on the fetal growth of guinea pigs and their ability to survive induced intrapartum asphyxia. Am J Obstet Gynecol. 2008;198:127.e1-6.

11. Satterfield MC, Bazer FW, Spencer TE, Wu G. Sildenafil citrate treatment enhances amino acid availability in the conceptus and fetal growth in an ovine model of intrauterine growth restriction. J Nutr. 2010;140:251-8.

12. Wareing M, Myers JE, O'Hara M, Baker PN. Sildenafil citrate (Viagra) enhances vasodilatation in fetal growth restriction. J Clin Endocrinol Metab. 2005;90: 2550-5.

13. Oyston CJ, Stanley JL, Baker PN. Potential targets for the treatment of preeclampsia. Expert Opin Ther Targets. 2015;19:1517-30.

14. Lacassie HJ, Germain AM, Valdés G, Fernández MS, Allamand F, López H. Management of Eisenmenger syndrome in pregnancy with sildenafil and Larginine. Obstet Gynecol. 2004;103(5 Pt 2):1118-20.

15. Sun X, Wang K, Wang W, Li B. Clinical study on sildenafil treatment of pregnant women with pulmonary arterial hypertension. Zhonghua Fu Chan Ke Za Zhi. 2014;49(6):414-8.

16. Samangaya RA, et al. A randonised double blinded placebo-controlled study of the phosphodiesterase type 5 inhibitor sildenafil for the treatment of preeclampsia. Hypertens Pregnancy. 2009;28:369-82.

17. von Dadelszen $P$, et al. Sildenafil citrate therapy for severe early-onset intrauterine growth restriction. BJOG. 2011;118(5):624-8.

18. Lin TH, YN S, Shih JC, Hsu HC, Lee CN. Resolution of high uterine pulsatility index and notching following sildenafil citrate treatment in a growthrestricted pregnancy. Ultrasound Obstet Gynecol. 2012;40(5):609-10.

19. Panda S, Das A, Md Nowroz H. Sildenafil citrate in fetal growth restriction. J Reprod Infertil. 2014;15(3):168-9.

20. Molelekwa V, Akhter P, McKenna P, Bowen M, Walsh K. Eisenmenger's syndrome in a 27 week pregnancy-management with bosentan and sildenafil. Ir Med J. 2005;98(3):87-8.

21. Streit M, Speich R, Fischler M, Ulrich S. Successful pregnancy in pulmonary arterial hypertension associated with systemic lupus erythematosus: a case report. J Med Case. 2009;3:7255.

22. Ganzevoort W, Alfirevic Z, von Dadelszen P, Kenny L, Papageorghiou A, van Wassenaer-Leemhuis A, Gluud C, Mol BW, Baker PN. STRIDER: Sildenafil therapy in dismal prognosis early-onset intrauterine growth restriction-a protocol for a systematic review with individual participant data and aggregate data meta-analysis and trial sequential analysis. Syst Rev. 2014;3:23.

23. Protocol STRIDER New Zealand/Australia: [doi:10.5281/zenodo.56150].

24. Protocol STRIDER Canada: [doi:10.5281/zenodo.56152].

25. Protocol STRIDER United Kingdom: [doi:10.5281/zenodo.56153].

26. Protocol STRIDER The Netherlands: [doi:10.5281/zenodo.56148].

27. Protocol STRIDER Ireland: [doi:10.5281/zenodo.496143].

28. DMC Charter STRIDER New Zealand/Australia: [doi:10.5281/zenodo.56149].

29. DMC Charter STRIDER Canada: [doi:10.5281/zenodo.56151].

30. DMC Charter STRIDER United Kingdom: [doi:10.5281/zenodo.56154].

31. DMC Charter STRIDER The Netherlands: [doi:10.5281/zenodo.56147].

32. DMC Charter STRIDER Ireland: [doi:10.5281/zenodo.535768]. 
33. Kjaergard LL, Villumsen J, Gluud C. Reported methodologic quality and discrepancies between large and small randomized trials in meta-analyses. Ann Intern Med. 2001;135(11):982-9.

34. Savovic J, Jones HE, Altman DG, et al. Influence of reported study design characteristics on intervention effect estimates from randomized, controlled trials. Ann Intern Med. 2012;157:429-38.

35. Wood L, Egger M, Gluud LL, et al. Empirical evidence of bias in treatment effect estimates in controlled trials with different interventions and outcomes: meta-epidemiological study. BMJ. 2008;336:601-5.

36. Chan AW, Hrobjartsson A, Haahr MT, Gotzsche PC, Altman DG. Empirical evidence for selective reporting of outcomes in randomized trials: comparison of protocols to published articles. JAMA. 2004;291 (20):2457-65.

37. Skoog M, Saarimäki JM, Gluud C, Sheinin M, Erlendsson K, Aamdal S, et al. Transparency and registration in clinical research in the Nordic countries. Nordic Trial Alliance, NordForsk; 2015 1-108.

38. Garattini S, Jakobsen JC, Wetterslev J, Berthele V, Banzi R, Rath A, et al. Evidence-based clinical practice: overview of threats to the validity of evidence and how to minimise them. European J Intern Med. 2016;32:13-21.

39. Järvinen et al. On blinded analysis and conclusions. J Clin Epidemiol 67 (2014) $769 \mathrm{e} 772$

40. Lundh A, Sismondo S, Lexchin J, Busuioc OA, Bero L. Industry sponsorship and research outcome. Coch Database Syst Rev. 2012;12:MR000033.

41. Little RJ, D'Agostino R, Cohen ML, Dickersin K, Emerson SS, Farrar JT, Frangakis C, Hogan JW, Molenberghs G, Murphy SA, Neaton JD, Rotnitzky A Scharfstein D, Shih WJ, Siegel JP, Stern H. The prevention and treatment of missing data in clinical trials. N Engl J Med. 2012;367:1355-60.

42. Molenberghs G, Kenward MG. Missing data in clinical studies. Chichester: Wiley; 2007.

\section{Submit your next manuscript to BioMed Central and we will help you at every step:}

- We accept pre-submission inquiries

- Our selector tool helps you to find the most relevant journal

- We provide round the clock customer support

- Convenient online submission

- Thorough peer review

- Inclusion in PubMed and all major indexing services

- Maximum visibility for your research

Submit your manuscript at www.biomedcentral.com/submit 